\title{
O livro didático de história hoje: um panorama a partir do PNLD
}

Sonia Regina Miranda

Universidade Federal de Juiz de Fora

Tania Regina de Luca

Unesp-Assis

\section{ReSUMO}

$\mathrm{O}$ artigo objetiva delinear uma breve radiografia do livro didático contemporâneo em função de algumas temáticas centrais que têm ocupado o cenário de investigações relativas ao saber histórico escolar, porém sob o escopo daquilo que se apresentou no interior dos processos de inscrição, triagem e avaliação das obras inscritas para o Programa Nacional do Livro Didático para o ano de 2005. Consideraram-se, para efeito de categorização global, os resultados dessa última avaliação de livros de História, divulgada no início de 2004, na qual as autoras desempenharam papéis vinculados diretamente à execução do processo avaliativo.

Palavras-chave: Livro didático de História; PNLD; Ensino de História.

\section{AbSTRACT}

The main objective of this article is to point out a brief radiography of contemporary Historic didactic books, analyzed from some central thematic present on the investigations related to educational knowledge. The example is formed by the book collection that participated on 2005 National Program of Didactics Books (PNLD), sponsored by Brazilian government. In order to compose a global categorization were used the results of the last History books evaluation, published in the beginning of 2004. The authors had participated in the execution of the whole process of evaluation.

Keywords: History didactic books; National Program of Didactic Books (PNLD); Teaching History.

É assente, entre os historiadores, que os sujeitos sempre se posicionam a partir de um lugar social e que os olhares que assumem são permanentemente contingenciados por circunstâncias que emergem em função de tais lugares. Parece pertinente, portanto, que se faça um esclarecimento inicial acerca 
do lugar a partir do qual se enunciam as análises aqui apresentadas, referentes ao perfil do livro didático de História hoje.

Enquanto membros, respectivamente, da Comissão Técnica do MEC e da Coordenação da Área de História para a avaliação do livro didático, não poderíamos apresentar as perspectivas compreensivas a respeito dessa ferramenta pedagógica de modo desvinculado dessa posição específica. Nesse sentido, procura-se delinear uma breve radiografia do livro didático contemporâneo em função de algumas temáticas centrais que têm ocupado o cenário de investigações relativas ao saber histórico escolar, porém sob o escopo daquilo que se apresentou no interior dos processos de inscrição, triagem e avaliação das obras para o PNLD 2005 e, mais especificamente, dos resultados globais dessa última avaliação de livros de História, cujos resultados vieram a público no início de 2004.

\section{POLÍTICAS PÚBLICAS PARA O LIVRO DIDÁTICO E O MERCADO EDITORIAL}

Contrariamente à apreensão predominante no âmbito do senso comum, o livro didático é um produto cultural dotado de alto grau de complexidade e que não deve ser tomado unicamente em função do que contém sob o ponto de vista normativo, uma vez que não só sua produção vincula-se a múltiplas possibilidades de didatização do saber histórico, como também sua utilização pode ensejar práticas de leitura muito diversas. ${ }^{1}$ Tampouco os efeitos da ação avaliativa implementada pelo Ministério da Educação podem ser vistos exclusivamente com base em uma premissa homogeneizadora de práticas e perspectivas quanto à História, sobretudo se considerarmos um breve histórico a respeito do papel regulador e/ou intervencionista do Estado nesse nicho particular de mercado e as circunstâncias políticas contemporâneas resultantes da prática avaliativa.

Observando-se a cronologia das ações do governo brasileiro em relação ao livro didático, constata-se que, embora a estruturação de um programa de avaliação determinante dos processos de compra seja algo relativamente recente, o estabelecimento de uma política pública para o livro didático remonta ao Estado Novo, quando se instituiu, pela primeira vez, uma Comissão Nacional de Livros Didáticos, cujas atribuições envolviam o estabelecimento de regras para a produção, compra e utilização do livro didático. ${ }^{2}$

Naquele contexto, a despeito da diversidade de projetos políticos e culturais, reservava-se à educação lugar privilegiado na formação da nacionali- 
dade, tarefa assumida pelo Ministério da Educação e Saúde, que não descuidou do controle do material educativo utilizado pela população escolar. ${ }^{3}$ Nesse sentido, a educação constituiu-se em veículo privilegiado para introdução de novos valores e modelagem de condutas, sobretudo com base nos mecanismos prescritivos no campo do currículo e do material instrucional, dentre os quais o livro didático emergia como peça ideológica fundamental, que desempenha importante papel estratégico na difusão dos valores apregoados pelo regime. ${ }^{4}$

Sob o período militar, a questão da compra e distribuição de livros didáticos recebeu tratamento específico do poder público em contextos diferenciados - 1966, 1971 e 1976 — todos marcados, porém, pela censura e ausência de liberdades democráticas. De outra parte, esse momento foi marcado pela progressiva ampliação da população escolar, em um movimento de massificação do ensino cujas conseqüências, sob o ponto de vista da qualidade, acabariam por deixar marcas indeléveis no sistema público de ensino e que persistem como o seu maior desafio. ${ }^{5}$ Neste contexto particular, destaca-se o peso da interferência de pressões e interesses econômicos sobre a história ensinada, na medida em que os governos militares estimularam, por meio de incentivos fiscais, investimentos no setor editorial e no parque gráfico nacional que exerceram papel importante no processo de massificação do uso do livro didático no Brasil. ${ }^{6}$ Cabe destacar que a associação entre os agentes culturais e o Estado autoritário transcendeu a organização do mercado consumidor da produção didática e envolveu relações de caráter político-ideológico, cujas repercussões sobre o conteúdo dos livros didáticos foram marcantes, sobretudo pela perspectiva de civismo presente na grande maioria das obras, bem como pelo estímulo a uma determinada forma de conduta do indivíduo na esfera coletiva.

A problematização e a teorização relativas a esse contexto histórico particular acabariam por gerar discussões a respeito da formação da consciência histórica pensadas genericamente sob o ponto de vista da manipulação, do controle ideológico e da formação de mentes acríticas em função de falsificações deliberadamente inseridas no material didático destinado às crianças e aos jovens. Vários trabalhos acadêmicos debruçaram-se sobre a produção didática nacional desse período e evidenciaram os compromissos ideológicos subjacentes, seu caráter manipulador, falsificador e desmobilizador, que mal disfarçava o intento de formar uma geração acrítica. ${ }^{7}$ Em relação à história ensinada, a alusão às perspectivas analíticas ensejadas, sobre- 
tudo por Marc Ferro, ${ }^{8}$ constituía-se como uma tendência acadêmica sistemática que acabaria por exercer um papel importante no sentido de constituir uma forma de pensar o livro didático de História e as políticas públicas a ele associadas exclusivamente enquanto políticas sociais discriminatórias e homogeneizadoras.

A partir da década de 1980, na conjuntura da reconstrução democrática, algumas tímidas ações no âmbito da Fundação de Assistência ao Estudante tangenciaram a discussão acerca dos problemas presentes nos livros didáticos distribuídos no território nacional. Esse movimento coincidiu com importantes debates a respeito dos programas oficiais de História, levados a efeito, sobretudo - mas não exclusivamente - nos estados de Minas Gerais e São Paulo. Marco na política em relação aos materiais didáticos foi a criação, em 1985, do Programa Nacional do Livro Didático — PNLD. A partir desse momento, progressivamente foram sendo incluídas no programa as distintas disciplinas componentes do currículo escolar e o programa foi se delineando no sentido de incorporar os professores no processo de escolha. Cabe destacar, contudo, em relação a esse aspecto, a existência de pontos de estrangulamento derivados, sobretudo, da segmentação formal entre o MEC — instância de planejamento e normatização do programa — e o FNDE — braço administrativo e executor das ações que envolvem o processo de escolha, compra e distribuição das obras. Tais problemas, que remontam à origem do programa em sua versão atual, ainda hoje carecem de equacionamento sistemático e se apresentam como um desafio a ser enfrentado pelos gestores das políticas públicas. Pesquisas realizadas em território nacional e patrocinadas pelo próprio MEC indicaram, ${ }^{9}$ em momentos distintos, que há problemas incontestáveis envolvendo atrasos sistemáticos na edição e distribuição do guia para as escolas, incongruências de toda ordem no tocante à escolha feita pelos professores e envio das obras pelo FNDE, atrasos na recepção dos livros por parte das escolas, bem como fragilidades envolvendo o processo de utilização das obras enviadas, que chegam até mesmo a ser desprezadas e desconsideradas pelos professores. Todos esses problemas, no entanto, derivam do processo de operacionalização administrativa do programa e, portanto, escapam por completo à competência da comissão avaliadora, que não tem nenhuma possibilidade de ingerência nessas questões. Vale destacar que todos os relatórios técnicos apresentados ao MEC insistiram, de forma sistemática e incisiva, na urgência de medidas que solucionem os problemas apontados.

Entretanto, foi apenas em 1996 — portanto num cenário político não 
mais caracterizado pela presença de um Estado autoritário, que se iniciou efetivamente a avaliação pedagógica dos livros didáticos, processo marcado por tensões, críticas e confrontos de interesses. Desde então, estipulou-se que a aquisição de obras didáticas com verbas públicas para distribuição em território nacional estaria sujeita à inscrição e avaliação prévias, segundo regras estipuladas em edital próprio. De um PNLD a outro, os referidos critérios foram aprimorados por intermédio da incorporação sistemática de múltiplos olhares, leituras e críticas interpostas ao programa e aos parâmetros de avaliação.

Em relação aos livros de História destinados ao segmento de $5^{\underline{a}}$ a $8^{\underline{a}}$ séries, foram realizados três processos consecutivos de avaliação vinculados, respectivamente, aos programas de 1999, 2002 e 2005. Cumpre destacar que houve variações de forma e substância em cada programa. Se, em 1999, cada volume era avaliado de modo unitário e independente frente à coleção, o que gerava circunstâncias conflitivas com relação à variabilidade no processo de escolha e uso das obras, tal situação foi alterada a partir do PNLD 2002, quando a unidade básica de avaliação e escolha passou a ser a coleção didática. Além disso, caminhou-se de um procedimento classificatório e distintivo, baseado em estrelas e menções discriminatórias, para um quadro meramente indicativo das obras aprovadas, o que modificou a própria organização do guia do Livro Didático que, na versão de 2005, apresenta-se ao professor como um catálogo organizado em ordem alfabética. Os critérios de avaliação, por sua vez, também foram sendo aprimorados, bem como as bases de cálculo utilizadas para a ponderação e tratamento estatístico das coleções avaliadas.

Ainda que o processo de aperfeiçoamento dos critérios e procedimentos de avaliação seja bastante recente, a relação de continuidade dessa política por quase uma década teve efeitos incontestáveis na forma e no conteúdo do livro didático brasileiro. $\mathrm{Na}$ área de História é patente a transformação: de um cenário marcado pelo predomínio de obras que veiculavam, de modo explícito ou implícito, todo tipo de estereótipo e/ou preconceitos, para um quadro em que predominam cuidados evidentes, por parte de autores e editores, em relação aos critérios de exclusão de uma obra didática. Nos vários editais e nos Guias publicados, tais critérios têm sido exaustivamente repetidos: existência de erros de informação, conceituais ou de desatualizações graves; veiculação de preconceitos de gênero, condição social ou etnia, bem como de quaisquer formas de proselitismo e, por último, verificação de incoerências 
metodológicas graves entre a proposta explicitada e aquilo que foi efetivamente realizado ao longo da obra. ${ }^{10}$

O fato de uma obra não estar presente no Guia publicado pelo MEC traz efeitos financeiros indesejáveis que, em alguns casos, culminaram no desaparecimento de editoras e/ou em fusões de grupos editoriais. A instituição de uma cultura avaliativa, num contexto político democrático, acabou por desencadear poderosos mecanismos de reajustamento e adaptação no mercado editorial.

Cumpre destacar que para o segmento voltado para as compras do setor público importa menos a orientação metodológica ou a ideologia contida em uma coleção didática e mais a sua capacidade de vendagem e aceitação no mercado. ${ }^{11}$ Nesse contexto, o livro didático assume claramente sua dimensão de mercadoria, sujeita a múltiplas interferências em seu processo de produção e vendagem. ${ }^{12} \mathrm{~A}$ esse respeito, há que se reconhecer que os pareceres técnicos de exclusão acabaram desempenhando, por vezes, papel primordial no processo de reformulação de coleções, patente no fato de um dos conjuntos excluídos em determinado PNLD vir a ser recomendado com distinção na edição seguinte do programa, o que indica o quanto o processo de avaliação foi tomado a sério por certos autores e editores. Outro ponto sensível, identificado em todas as pesquisas mais recentes a respeito da escolha de livros didáticos, está no desempenho agressivo das editoras no mercado, que se valem de sofisticados esquemas de distribuição e vendas, a ponto de influir decisivamente nos processos de escolha nas escolas de todo o país. Naturalmente, as empresas mais bem estruturadas desfrutam de larga vantagem frente às editoras menores.

Considerando-se o volume de recursos governamentais utilizados na aquisição e distribuição de livros didáticos, o setor editorial brasileiro estabeleceu fortes dependências em relação ao programa. Há que se destacar, ainda, a clara tendência em direção à monopolização do setor por algumas poucas empresas, como atestam as crescentes fusões ocorridas desde o advento do programa, o que possui indiscutíveis relações com as mudanças processadas ao longo dos processos avaliativos e com o movimento quantitativo de exclusões, conforme se pode depreender a partir dos dados apresentados no Gráfico 1: 


\section{Gráfico 1 - PNLD - Área de história-histórico \\ de inscrições e aprovações}

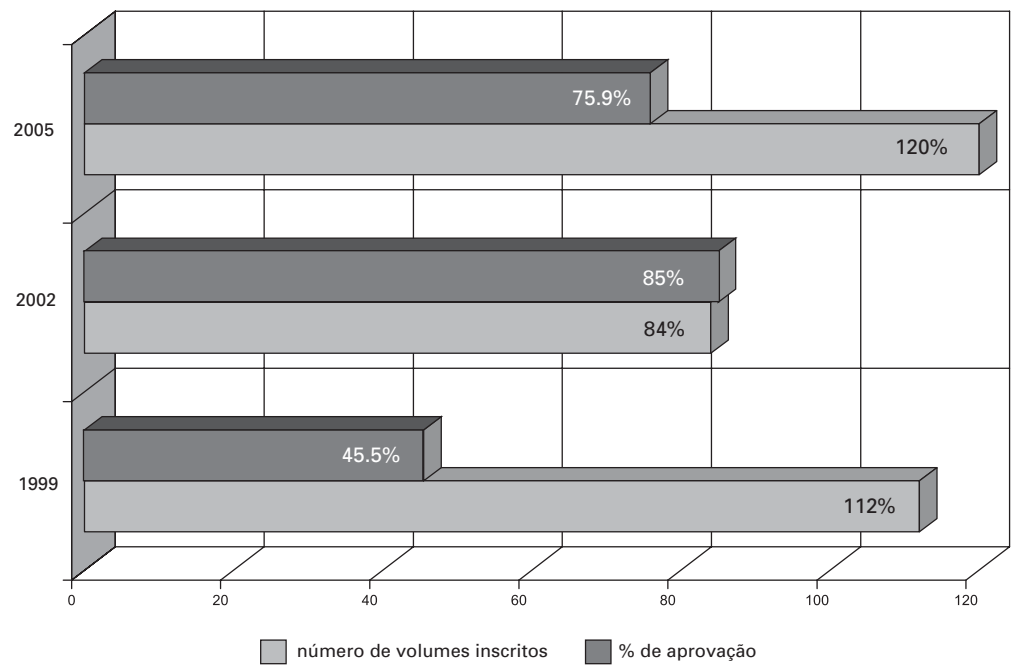

Fonte: Relatórios Técnicos MEC/SEF.

Vale lembrar, mais uma vez, que para o PNLD 1999 tanto a inscrição de obras por editora como a avaliação pedagógica foram feitas por volumes isolados, o que não implica a necessidade de a editora possuir uma coleção completa. Tal cenário modificou-se a partir do PNLD 2002, quando se observou redução no número geral de coleções inscritas, quadro que novamente se alteraria no programa de 2005, com nova elevação do número de inscrições. Foi também a partir de 2002 que a avaliação na área de História incorporou a análise estatística, feita a partir de planilhas de cálculos, nas quais se registrou o desempenho de cada coleção em relação aos quesitos que compunham a ficha de avaliação, sempre divulgada nos Guias. Não se registraram modificações significativas nas fichas de 2002 para 2005, embora tenham sido redefinidos os valores ponderados dos quesitos gerais. ${ }^{13}$ Essas mudanças projetam para as editoras demandas de adaptação que têm sido assimiladas com maior ou menor agilidade, em razão do porte da empresa e de sua participação no mercado.

As profundas transformações ocorridas em tão breve período modificaram o perfil dos grupos editoriais no mercado do livro didático de História. Na primeira avaliação empreendida, o cenário de distribuição de obras por editoras era o do Gráfico 2: 


\section{Gráfico 2 - PNLD 1999 - Número de coleções por editora}

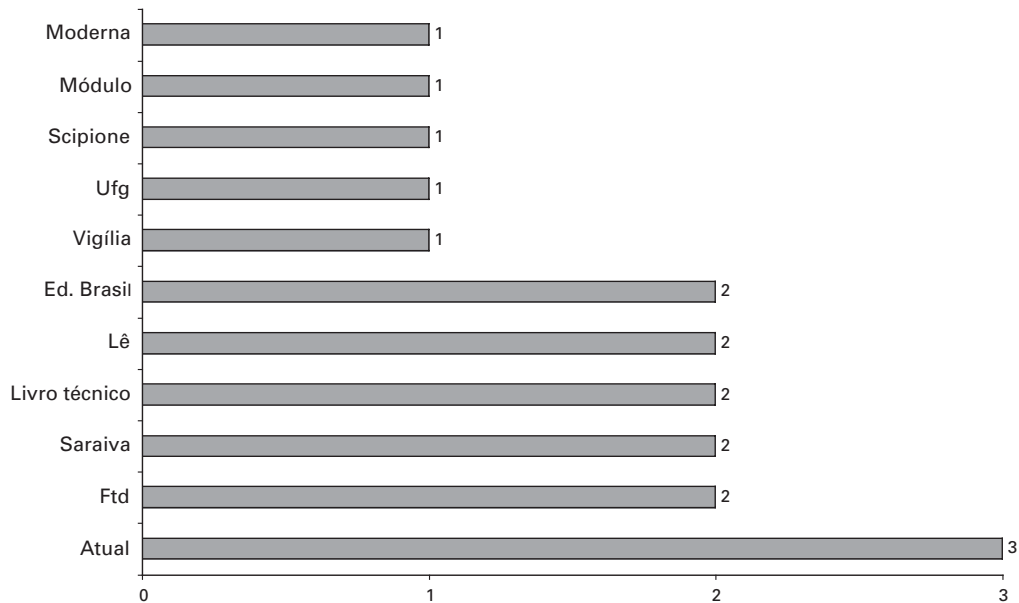

Fonte: Relatórios Técnicos MEC/SEF.

Tomando como referência o PNLD 2005, obtém-se um quadro significativamente distinto do inicial, como se pode ver no Gráfico 3:

Gráfico 3 - PNLD 2005 - Distribuição das obras por grupos editoriais - Áreas de história

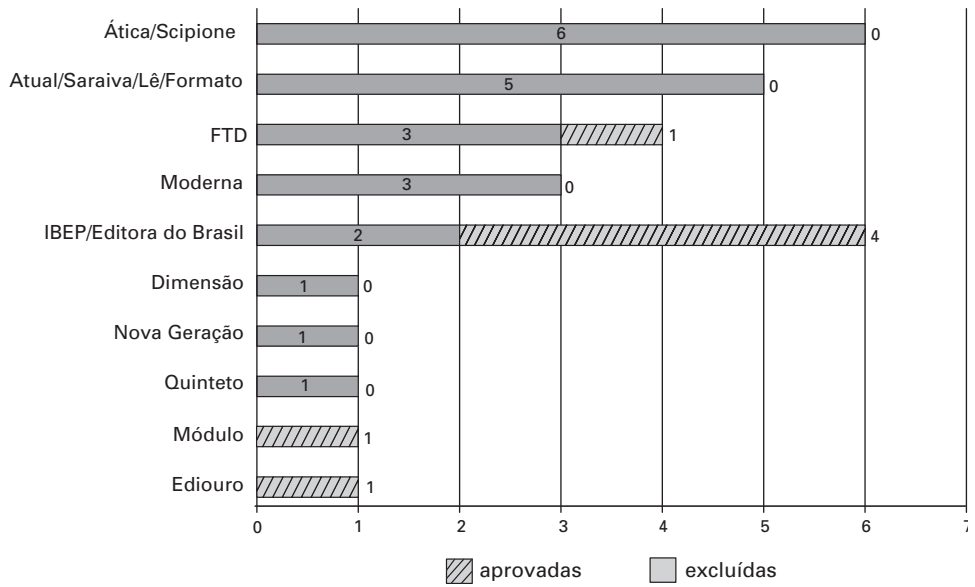

Fonte: Relatórios Técnicos MEC/SEF. 
Observa-se uma mudança muito significativa em relação ao grupo dominante e em relação à oferta de livros didáticos. Houve supressão de empresas, aparecimento de outras e, sobretudo, fusão de editoras, que formaram grandes conglomerados, com poderosa organização em termos de distribuição e divulgação e que tendem a assumir posições hegemônicas no mercado. Os impactos da exclusão de uma ou de várias coleções de uma mesma empresa podem significar sua inviabilidade econômica, sobretudo se o resultado negativo se repetir em outras disciplinas. Essa situação não pode ser abstraída quando se avaliam as críticas dirigidas ao programa por autores e editoras. Noutras palavras, se é certo que todo e qualquer processo de avaliação é problemático e sempre pode ter seus critérios questionados, é também evidente que no caso em apreço há um complexo jogo que atende a interesses bem definidos e que nem sempre se pauta por preocupações de ordem exclusivamente acadêmica.

O SABER HISTÓRICO ESCOLAR E O LIVRO DIDÁTICO DE HISTÓRIA: ALGUMAS QUESTÕES CONTEMPORÂNEAS

O cenário que emerge dos resultados da avaliação, vistos em perspectiva diacrônica, revela um quadro amplo e diversificado, que permite refletir a respeito das interfaces entre saberes históricos e pedagógicos.

Alain Choppin ${ }^{14}$ bem assinalou que os livros didáticos não são somente ferramentas pedagógicas, mas também suportes de seleções culturais variáveis, verdades a serem transmitidas às gerações mais jovens, além de meios de comunicação cuja eficácia repousa na importância de suas formas de difusão. Nessa perspectiva, os livros, para além de se constituírem em vetores ideológicos, são fontes abundantes, diversificadas e, ao mesmo tempo, completas, visto que cada obra constitui uma unidade própria e coerente, com princípio, meio e fim. Dois aspectos particulares distintos, porém articulados, merecem ser destacados quando se intenta radiografar os resultados da avaliação do livro didático: a diversidade dessa fonte e a lógica mercadológica que orienta sua produção.

A produção de livros didáticos envolve uma densa trama entre saberes de referência, autores e editoras. Já o seu consumo envolve tramas não menos imbricadas entre mercado, projetos escolares, compradores e leitores finais. Entre uma ponta e outra, os efeitos normatizadores implementados pela ação avaliadora vinculada ao Estado agregam elementos que não podem ser des- 
prezados na compreensão das relações possíveis entre produção e consumo, uma vez que os efeitos determinantes do mercado impõem limites ao processo de renovação do perfil das obras e ao diálogo entre o saber escolar didatizado e os saberes provenientes das ciências de referência. Porém, não se podem desprezar os elos possíveis entre a prática de avaliação vinculada a essa política pública e o seu efeito indutor quanto às dimensões do saber histórico escolar presentes nas obras didáticas.

O fato de se compreender o livro didático na sua complexidade e diversidade fez que, no âmbito da Coordenação de área e Comissão Técnica, desde o advento dos processos regulares de avaliação, a dimensão não prescritiva fosse uma meta a ser alcançada e aprimorada por todos os envolvidos no trabalho. É importante ressaltar que cada coleção sempre foi avaliada individualmente e sem nenhum critério preestabelecido em termos de seu enquadramento conceitual. Todas as avaliações realizadas até o PNLD 2005 pautaram-se pelo edital público e seguiram rigorosamente o que foi estabelecido nesse documento de caráter público. Da análise de cada conjunto de quatro volumes inscritos e que perfaz a coleção, resultou uma planilha de desempenho e sua respectiva resenha. Do trabalho de avaliação, resultam instrumentos que permitem interpretações de cunho comparativo envolvendo todas as coleções inscritas para avaliação, conforme as aqui ensaiadas.

Atentando para os resultados alcançados pelas coleções inscritas no PNLD 2005 nos grupos Metodologia da Aprendizagem e Metodologia da História, ${ }^{15}$ pode-se avaliar, com precisão, o nível de diversidade que particulariza a amostra, aqui referenciada por meio de números seqüenciais que aparecem no eixo horizontal do Gráfico 4.

A linha pontilhada contínua informa o desempenho obtido pelas 28 coleções inscritas. No final, foram 22 as aprovadas e 6 as excluídas, ${ }^{16}$ estas últimas representadas no gráfico a partir do ponto 23 . Em torno da linha pontilhada oscila uma linha preta mais espessa, que dá conta do resultado obtido em relação ao quesito Metodologia da Aprendizagem, e uma linha branca, relativa ao quesito Metodologia da História. As relações que se estabelecem entre esses dois quesitos estruturantes para a composição do perfil de uma obra didática podem fornecer pistas interessantes acerca das múltiplas possibilidades de organização e encaminhamento de propostas pedagógicas e de ensino da História.

Observem-se, por exemplo, os casos marcados na linha horizontal sob os números 11 e 19. Embora esta última coleção tenha apresentado desempenho final sensivelmente inferior em relação à de número $11-1,8$ pontos de 
Gráfico 4 - PNLD - Desempenho das coleções na área de História

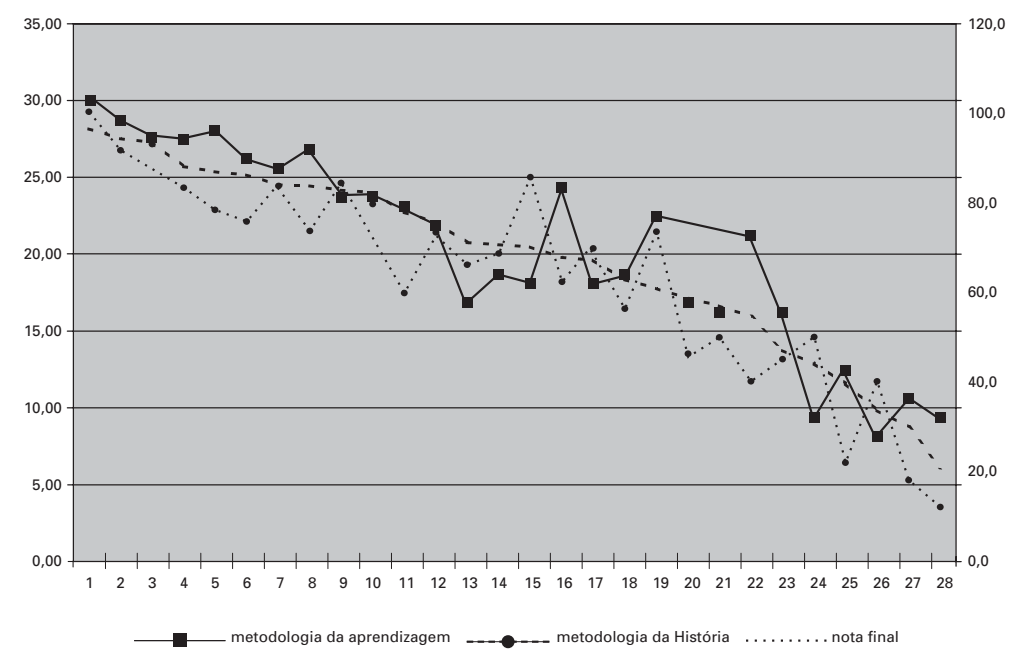

Fonte: Relatórios Técnicos MEC/SEF.

diferença —, no cômputo geral a coleção 19 apresenta maior equilíbrio entre abordagem metodológica da História, proposições de didatização e diálogo com os saberes dos estudantes. Tal fato é registrado no gráfico pela aproximação entre as duas linhas, no caso da coleção 19, e pelo seu sensível distanciamento, para a coleção 11. Esse distanciamento também é perceptível em outros casos, como ocorre com as coleções 5, 8, 15, 16 e 22. Portanto, o montante obtido pela coleção 19 vincula-se a outros quesitos associados a circunstâncias secundárias frente àquilo que se considerou essencial para uma obra didática, isso é, o diálogo entre o saber de referência e o saber escolar. Esta é uma das razões que justificam o fim das menções distintivas, que apresentavam uma classificação das coleções que não fazia jus à diversidade observada nos vários conjuntos analisados em três programas.

É fundamental ressaltar que o quadro resultante do processo de avaliação é marcado por enorme variabilidade de perspectivas metodológicas, temáticas, recortes e possibilidades pedagógicas; em síntese, não se observa a tão propalada homogeneidade.

No Brasil, data da década de 1990 a discussão a respeito das dimensões inerentes à Didática da História, problemática que tem se renovado constantemente desde então. Klaus Bergmann, ${ }^{17}$ já no início dos anos 90 introduzia 
no Brasil uma discussão que hoje se renova através da divulgação em língua portuguesa das abordagens propostas por Jorn Russen ${ }^{18}$ a respeito das dimensões inerentes à Didática da História. Segundo Bergmann, "refletir sobre a História a partir da preocupação da Didática da História significa investigar o que é apreendido no ensino da História (é a tarefa empírica da Didática da História), o que pode ser apreendido (é a tarefa reflexiva da Didática da História) e o que deveria ser apreendido (é a tarefa normativa da Didática da História)" ${ }^{19}$ Isso significa dizer que, ao se discutir a natureza e as dimensões do saber histórico escolar, é preciso levar em consideração as múltiplas faces desse saber, desde os planos de prescrição até as representações difundidas a seu respeito e os efeitos da consciência histórica dentro e fora da escola, sem desprezar os processos objetivos de apreensão do conhecimento histórico pelos alunos e a construção de conceitos dele derivados. Os livros didáticos de História se apresentam, até pelo seu enorme grau de difusão, potencializado pela distribuição gratuita aos estudantes de escola pública de todo o país, como uma das mais importantes formas de currículo semi-elaborado, que nasce a partir de distintas visões e recortes acerca da cultura. ${ }^{20}$ Carregam consigo, portanto, múltiplas possibilidades de organização dessa relação entre o que é, o que pode ser e o que deveria ser aprendido em relação à disciplina.

A partir do PNLD é possível depreender tendências globais quanto à História ensinada que se vinculam mais a tipos diferenciados de saberes disciplinares, curriculares e/ou derivados de tradições pedagógicas distintas ${ }^{21}$ do que aos efeitos supostamente normativos do programa. Os resultados globais da avaliação constituem-se em fonte privilegiada para compor um quadro compreensivo a respeito de tendências contemporâneas da História, ou melhor, das Histórias, que se quer ver ensinadas.

Sobre essa ótica, busca-se apresentar um mapeamento das coleções inscritas no último PNLD, em função de quatro temáticas centrais, selecionadas por serem especialmente caras às pesquisas e discussões contemporâneas que tomam o saber histórico escolar enquanto objeto específico de investigação: a perspectiva quanto à visão de História, a relação com o processo de construção de conhecimento pelo aluno, a orientação curricular e a relação genérica com o desenvolvimento da Historiografia. Para a apresentação detalhada de cada um desses blocos temáticos, empreendeu-se um esforço taxonômico com finalidade estritamente didática, e vale alertar que se tem plena consciência de que os agrupamentos poderiam receber outras designações.

Pierre Vilar, ${ }^{22}$ ao discutir a especificidade do vocabulário histórico e os conceitos mobilizados pelos historiadores, chama atenção para o duplo sen- 
tido da noção de História, aspecto igualmente já ressaltado por Marc Bloch. As palavras de Vilar, a "História designa ao mesmo tempo o conhecimento de uma matéria e a matéria desse conhecimento". Em relação a essa ambigüidade, Keith Jenkins ${ }^{23}$ também insiste na separação, temporal e espacial, entre o passado e a História: uma coisa é o recorte de tempo em que algo se passou, outra coisa é a narrativa construída sobre esse recorte, cuja lógica é diretamente pertinente ao tempo de sua produção enquanto narrativa e não ao tempo original do acontecimento.

O fato central que interessa destacar é que essa ambigüidade está posta nos múltiplos projetos possíveis para a História ensinada e que ela pode ser claramente depreendida a partir de um olhar sobre o conjunto dos manuais didáticos avaliados no PNLD 2005. Sobre esse aspecto, distinguiram-se três possibilidades de abordagem. Há um grupo de obras que apresentam uma organização de conteúdos, atividades e textos articulados de acordo com um agrupamento que se poderia designar como procedimental e, nesse sentido, valoriza a dimensão formativa que advém do procedimento histórico e do tipo de leitura e problematização de fontes que caracteriza a ação do historiador, com ênfase em habilidades relacionadas à leitura, identificação de informações, análise, comparações, bem como em discussões que priorizam um olhar sobre o contemporâneo; outro grupo cuja seleção de conteúdos, cronologia e textos é feita segundo uma visão mais informativa acerca da narrativa acontecimental do passado e que, nesse sentido, prioriza aquela dimensão que Vilar nos aponta como "conhecimento de uma matéria"; e, finalmente, um terceiro grupo, que pela ausência de uma expressão mais precisa, designou-se de "visão global", por buscar articular, com relativo sucesso, as duas dimensões citadas, isto é, não abre mão da informação histórica derivada de um conhecimento socialmente acumulado, bem como dos recortes canônicos de conteúdo, mas explora também a dimensão construtiva do conhecimento histórico, problematiza as fontes, apresenta elementos que garantem a alunos e professores a compreensão acerca da dimensão de provisoriedade da explicação histórica.

Os aspectos descritos podem ser entendidos como indicadores relativos ao grau de atualização das coleções em relação aos debates a respeito da dimensão formativa do saber histórico escolar que, de certo modo, tem se feito muito presente nas pesquisas contemporâneas a respeito da História ensinada. Em termos quantitativos, os resultados são os apresentados no Gráfico 5, considerando-se as coleções que passaram pela análise: 
Gráfico 5 - PNLD 2005 - Perspectiva de História veiculada pelas coleções

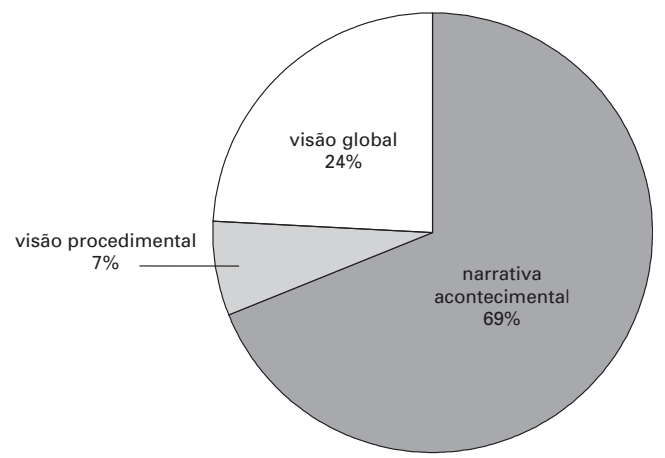

Fonte: Elaborado a partir dos Relatórios Técnicos MEC/SEF e Pareceres técnicos das coleções.

A despeito do desenvolvimento dos debates relativos à história ensinada e da crítica à ênfase em uma abordagem acontecimental e essencialmente informativa sobre o conteúdo histórico, quando se observa o perfil dos produtos que emanam da indústria editorial e sua inserção no mercado, constatase que é ainda essa a perspectiva dominante. No entanto, não podemos desconsiderar o fato de que, embora a abordagem relativa a uma visão procedimental da História — somada àquilo que aparece aqui designado como visão global — seja quantitativamente secundária frente à visão acontecimental, que é hegemônica, deve-se ter presente que a projeção dessa perspectiva em meio a um universo maior projeta de modo objetivo, para a indústria cultural, uma possibilidade alternativa em relação à cultura histórica posta e, neste sentido, esse grupo numericamente inferior tende a cumprir um papel importante enquanto artífice de uma nova possibilidade pedagógica posta no âmbito das reflexões sobre o ensino.

Vinculado a esse primeiro bloco temático, porém com uma nítida especificidade no campo da pesquisa acadêmica sobre a História ensinada, emerge um segundo agrupamento possível, com ênfase nas questões relativas à cognição e aprendizagem. Há muito que as chamadas ciências da educação vêm se debruçando em pesquisas e discussões teóricas derivadas de um olhar que se desloca do "como se ensina" para o "como se aprende", e não caberia enveredar por uma discussão específica a respeito de teorias cognitivas.

No Brasil, o reflexo desse deslocamento na discussão relativa à História 
ensinada acabou por ensejar uma série de estudos relativamente recentes, bem como grupos de pesquisa ainda em processo de conformação, cujo foco essencial recai sobre a questão da construção da temporalidade e da aprendizagem dos conceitos históricos pelo aluno. ${ }^{24}$ Neste sentido é possível apreender, com base na análise e categorização das obras didáticas, a existência de diferentes perspectivas compreensivas acerca da aprendizagem, bem como dos diálogos que podem ser estabelecidos entre as ferramentas didáticas utilizadas e os saberes prévios do aluno.

Considerando-se a diversidade de possibilidades teóricas que compreendem os processos cognitivos, bem como as interfaces possíveis que podem surgir, em uma mesma obra didática, de abordagens sócio-interacionistas e piagetianas, optou-se por utilizar uma classificação genérica que, embora possa esbarrar nos riscos inerentes à arbitrariedade dos conceitos, ilustra grosso modo aquilo que se pretende demonstrar.

Por um lado, identifica-se um conjunto de obras que assumem perspectiva de transmissão vertical de conteúdos e, nesse sentido, a abordagem de técnicas e recursos didáticos vincula-se menos às estratégias de apresentação dos temas e de exposição dos conteúdos do que aos exercícios e atividades propostos para os alunos. Para fins puramente didáticos, designou-se a perspectiva de aprendizagem assumida de modo explícito ou subliminar por esse grupo como paradigma informativo. Nesse paradigma, os objetivos educacionais selecionados centram-se na obtenção da informação e do conteúdo histórico, independentemente de como tal conteúdo é processado pelo aluno sob o ponto de vista cognitivo; nesse sentido, o diálogo com os saberes dos estudantes, ou mesmo a proposição de situações cognitivas que possam gerar o entendimento por meio da comparação de tempos e/ou circunstâncias, é praticamente nulo.

Outra possibilidade de enfoque dessa questão traz, como pressuposto, exatamente a construção desse diálogo como um ponto de partida para a projeção de um recorte que seja significativo para o aluno, tanto no que se refere ao recorte temático, quanto às possibilidades de explicação e estabelecimento de analogias. Esse segundo paradigma será tratado, aqui, como 'cognitivista'. Ainda que sejam muitas as possibilidades de organização didática das obras - e, nesse particular seria possível projetar um quadro bastante diversificado sob o ponto de vista das filiações teóricas que sustentam as operações de seleção —, pode-se dizer que, nessas obras, considera-se genericamente uma base de saberes prévios dos alunos como ponto de partida para uma aprendizagem significativa. As obras constituídas sob tal orientação dia- 
logam com tais referências a partir de uma postura que valoriza a problematização enquanto forma de estabelecer relações entre passado e presente. Busca-se, de modo geral, promover a aquisição gradual dos conceitos que, nesse caso, se sobrepõem às definições mecânicas e, coerentemente com tal opção, os momentos de introdução das unidades, as atividades e exercícios são propostos com a intenção de propiciar circunstâncias dialógicas e de construção conceitual. Considerando-se a relação entre tais premissas e uma trilha mais recente de investigação e abordagem da História ensinada, esse segundo conjunto apresenta-se numericamente inferior em relação ao primeiro grupo, ainda hegemônico no mercado de livros didáticos. A presença desses dois paradigmas no interior do conjunto analisado pode ser observada com base no Gráfico 6.

\section{Gráfico 6 - PNLD 2005 - Perspectivas de aprendizagem presentes nas coleções}

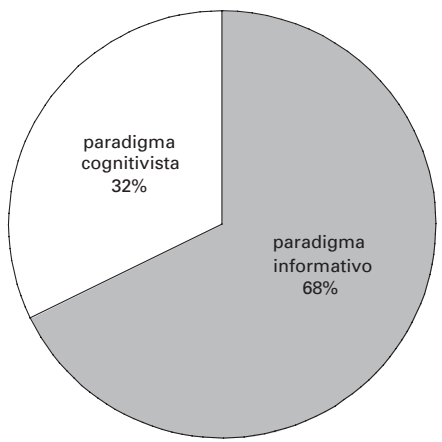

Fonte: Elaborado a partir dos Relatórios Técnicos MEC/SEF e Pareceres técnicos das coleções.

É possível, também, pensar um macro-agrupamento das coleções segundo uma temática bastante recorrente em relação à discussão relativa à história ensinada: a abordagem programática que orienta as operações de seleção e a organização temática das coleções. A proporção entre grupos, nesse caso, apresenta-se expressa no Gráfico 7: 
Gráfico 7 - PNLD - Perspectiva programática dominante

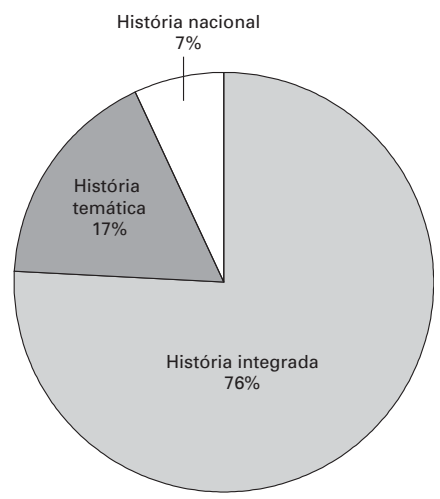

Fonte: Elaborado a partir dos Relatórios Técnicos MEC/SEF e Pareceres técnicos das coleções.

Ao se levar em conta a variabilidade dos currículos de História e sua relação com a história da História ensinada no Brasil, vislumbra-se um cenário mais global, no qual programas distintos se transformaram em textos oficiais, pertinentes a diferentes cenários históricos e que acabaram por se converter em tradições distintas, sustentadas essencialmente naquilo que Chesneaux ${ }^{25}$ designou como quadripartição histórica, da qual somos todos tributários, dada sua profunda interferência nos processos de formação de professores. ${ }^{26} \mathrm{Em}$ certa medida, essa tradição encontra-se presente nas obras que fazem uma opção pela abordagem da chamada História integrada, isto é, pelo tratamento da História da civilização ocidental de modo articulado com os conteúdos de História do Brasil e História da América. Prioriza-se, desse modo, a compreensão do processo histórico global, tendo por eixo condutor uma perspectiva de tempo cronológica e sucessiva, definida a partir da evolução européia. Integram-se, a partir desse epicentro, as demais culturas não européias pelo viés cronológico. Esse é o grupo hegemônico, dentro do qual insere-se a maior parte das coleções.

Tal perspectiva, ancorada em uma visão eurocêntrica do tempo e do processo histórico, acabou por se vincular, ainda que sob diferentes recortes temáticos, a uma abordagem programática marcada pela valorização da identidade nacional, por intermédio da introdução dos conteúdos de História do Brasil no início da escolarização ou, mais precisamente, a partir do segundo segmento do ensino fundamental. De certo modo, a cultura instituída a par- 
tir da Reforma Capanema, que consagrou a separação entre a História Geral e a do Brasil, deixou marcas bastante notáveis sobre um modo específico de pensar a articulação das temáticas históricas. ${ }^{27}$ Somente após o estudo do Brasil, o aluno é inserido nas temáticas relacionadas à História Geral.

Verifica-se, ainda, um outro conjunto de coleções que acompanha a evolução historiográfica do pós-1960 e que procura redimensionar a idéia evolutiva e processual. Esse grupo rompe com a dimensão de tempo visto estritamente a partir da cronologia e multiplica as possibilidades temáticas que norteiam as operações de seleção. As obras didáticas organizadas sob tal diretriz apresentam grande diversidade de recortes e foi o grupo que mais cresceu em relação ao PNLD 2002.

Por fim, há que mencionar uma das temáticas mais complexas e que, para ser efetivamente explorada, demandaria investigação detalhada e pontual, dado o seu grau de diversidade temática. Trata-se de inquirir a respeito das relações que as coleções estabelecem com o desenvolvimento da historiografia e do modo como incorporam ou não as revisões derivadas de estudos contemporâneos no campo da pesquisa histórica. A análise permite apontar apenas algumas tendências mais globais.

É claramente perceptível a presença de um grupo predominante - que se designa genericamente como Tradicional - que aborda a História em sua dimensão meramente informativa e não valoriza o conhecimento histórico em seu aspecto construtivo. As narrativas são organizadas a partir de recortes já consagrados, as fontes históricas ganham caráter mais ilustrativo e não são exploradas numa dimensão que aproxime o aluno daquilo que preside o procedimento histórico; nesse sentido, uma concepção de verdade pronta e irrefutável preside a obra. Em geral, as coleções que integram esse subconjunto mantêm coerência com a visão processual e evolutiva do tempo e das sociedades e não rompe com a quadripartição clássica de base eurocêntrica. Alguns temas sustentam-se em uma historiografia tradicional e apresentam-se de modo absolutamente recorrente e naturalizado em termos de explicação, tais como: a explicação da economia brasileira a partir da teoria dos ciclos; a ausência de dinamismo econômico na economia colonial; a análise da sociedade colonial somente a partir do binômio patriarcalismo/submissão feminina; a compreensão da industrialização brasileira a partir do paradigma paulista, em associação estrita com a acumulação de capital cafeeiro, ${ }^{28}$ entre outras muitas possibilidades analíticas que podem emergir se procedermos a uma análise mais pontual, incabível nos limites deste texto. 
Outro grupo - indicado como Eclético — mantém a narrativa com base nos recortes clássicos de conteúdos, mas as obras abrem-se de modo significativo e relevante para uma renovação historiográfica de caráter tópico. Relativizam-se os paradigmas explicativos em relação a temáticas e pesquisas específicas que vêm sendo objeto de debates historiográficos nas últimas décadas e, nesse sentido, a explicação histórica ofertada ao aluno, com raras exceções, já não mais se baseia em paradigmas que foram objeto de revisão no campo historiográfico.

Há, por fim, um outro grupo — associado a uma historiografia Renova$d a$ - que rompe com a perspectiva tradicional e incorpora na seleção de conteúdos não só aquilo que advém da macro-renovação historiográfica do pós1960, como também os resultados das pesquisas contemporâneas na área dos estudos históricos. Considerando-se que a soma das duas últimas tendências não corresponde nem à metade das obras, é possível afirmar que ainda existe um enorme abismo entre a renovação historiográfica advinda da pesquisa historiográfica e o saber histórico veiculado por meio do livro didático, conforme se observa no Gráfico 8.
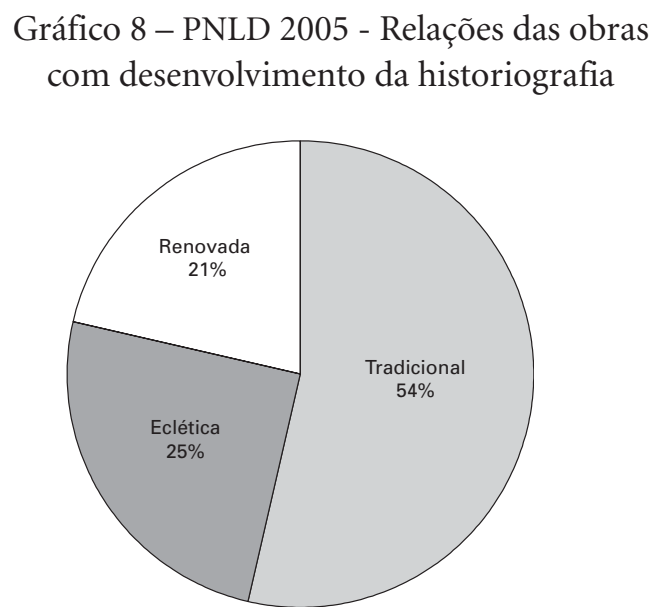

Fonte: Elaborado a partir dos Relatórios Técnicos MEC/SEF e Pareceres técnicos das coleções.

Cabe ressaltar, à guisa de conclusão, que não é possível estabelecer uma relação unívoca entre os grupos em função das quatro grandes temáticas abordadas, o que aponta para o grau de complexidade do conjunto analisado, as- 
pecto freqüentemente negligenciado nas avaliações a respeito da produção didática que, não raro, assumem perspectivas mais generalizantes.

Espera-se que os dados apresentados contribuam para o debate em torno da formação dos professores e das políticas públicas para os livros didáticos de História, bem como de seus múltiplos desdobramentos em relação à História ensinada e aos diversificados interesses e condicionantes que cercam a produção e a compra dessa mercadoria chamada livro.

\section{NOTAS}

${ }^{1}$ Sobre essa questão ver, entre outros, CHARTIER, R. (Org.) Práticas da leitura. São Paulo: Estação Liberdade, 1996; e CERTEAU, M. de. A invenção do cotidiano. Petrópolis: Vozes, 1996. Para uma discussão que aborda a temática específica do livro didático de História e as tramas que envolvem seus usos, ver BITTENCOURT, C. M. F. Livro didático e conhecimento histórico: uma história do saber escolar. São Paulo, 1993. Tese (Doutoramento) Universidade de São Paulo.

${ }^{2}$ BATISTA, A. A. G. (Org.) Recomendações para uma política pública de livros didáticos. Brasília: Ministério da Educação, SEF, 2002.

${ }^{3}$ SCHWARTZMAN, S. et al. Tempos de Capanema. São Paulo: Paz e Terra, FGV, 2000.

${ }^{4}$ CAPELATO, M. H. R. Multidões em cena: propaganda política no varguismo e peronismo. São Paulo: Papirus, 1998.

${ }^{5}$ CASTRO, C. de M. e CARNOY, M. (Org.) Como anda a reforma da educação na América Latina? Rio de Janeiro: FGV, 1997.

${ }^{6}$ FONSECA, S. G. Caminhos da história ensinada. São Paulo: Papirus, 1993.

${ }^{7}$ DEIRÓ, M. de L. C. As belas mentiras: a ideologia subjacente aos textos didáticos. São Paulo: Moraes, 1978; FREITAG, B. et al. O livro didático em questão. São Paulo: Cortez, Autores Associados, 1989; OLIVEIRA, J. B. A. et al. A política do livro didático. São Paulo: Sumis, Campinas: Ed. Unicamp, 1984.

${ }^{8}$ FERRO, M. Falsificações da História. Lisboa: Europa-América, s.d.

${ }^{9}$ BATISTA, A. A. G. (Org.) Escolha de livros didáticos de $1^{\underline{1}}$ a $4^{\underline{\underline{a}}}$ série: padrões e processos no PNLD. Brasília: MEC, SEF, 2002; e MIRANDA, S. R. O PNLD na escola: problemas, desafios e perspectivas. Relatório técnico apresentado ao MEC/SEF. Brasília, 2003.

${ }^{10}$ Sobre os critérios de exclusão e de classificação, incluindo a ficha utilizada na avaliação das obras, ver: GUIA DOS LIVROS DIDÁTICOS 2005. v.5. Brasília: Ministério da Educação, Secretaria de Educação Infantil e Fundamental, 2004. 
${ }^{11}$ FONSECA, op. cit., p.147.

${ }^{12}$ Cf. BITTENCOURT, C. Livros didáticos entre textos e imagens. In: (Org.) $O s a-$ ber histórico na sala de aula. 2.ed. São Paulo: Contexto, 1998.

${ }^{13}$ São considerados atualmente, para efeito de contabilização final e classificação das obras, os seguintes quesitos: Metodologia da Aprendizagem (30 pontos), Metodologia da História (30 pontos) Manual do Professor (15 pontos), Cidadania (15 pontos), Aspectos Editoriais (10 pontos).

${ }^{14}$ CHOPPIN, A. Pasado y presente de los manuales escolares. In: BERRIO, J. R. La cultura escolar de Europa: tendencias historicas emergentes. Madrid: Biblioteca Nueva, 2000.

${ }^{15}$ Selecionamos para esta discussão somente os quesitos Metodologia da História e Metodologia da Aprendizagem, em razão de seu peso na composição final das notas obtidas pelas coleções. Além desses quesitos, as coleções são também avaliadas em função dos quesitos anteriormente indicados.

${ }^{16}$ Duas coleções não foram pontuadas por terem sido excluídas, respectivamente, nos processos de triagem inicial e na pré-análise, em virtude de terem infringido as regras do edital. Cabe destacar, contudo, que o processo de triagem inicial é de responsabilidade exclusiva do IPT e do FNDE, e que as obras ali definidas como impedidas sequer chegam à comissão avaliadora para a análise pedagógica.

${ }^{17}$ BERGMANN, K. A História na reflexão didática. Revista Brasileira de História, São Paulo, v.9, n.19, fev.1990.

${ }^{18}$ RÜSSEN, J. Razão Histórica: Teoria da História, fundamentos da ciência histórica. Brasília, UnB, 2001.

${ }^{19}$ BERGMANN, K., op. cit., p.29.

${ }^{20}$ GIMENO SACRISTÁN, J. Currículo e diversidade cultural. In: SILVA, T. T., MOREIRA, A. F. Territórios contestados. Petrópolis: Vozes, 1995.

${ }^{21}$ GAUTHIER, C. et al. Por uma teoria da Pedagogia. Ijuí: Unijuí, 1998.

${ }^{22}$ VILAR, P. Iniciação ao vocabulário de análise histórica. Lisboa: Sá da Costa, 1985.

${ }^{23}$ JENKINS, K. A História repensada. São Paulo: Contexto, 2001.

${ }^{24} \mathrm{Em}$ um recorte historicizante, poderíamos apontar alguns ícones dessa linha investigativa tais como: ZAMBONI, E. O desenvolvimento das noções de espaço e tempo na criança. In: . (Org.) A prática do ensino de História. São Paulo: Cortez, 1985; NADAI, E., BITTENCOURT, C. M. F. Repensando a noção de tempo histórico no ensino. In: PINSKY, J. (Org.) O ensino de História e a criação do fato. 7.ed. São Paulo: Contexto, 1997; ARAÚJO, H. M. M. Tempo Rei: a noção de tempo em adolescentes de 10 a 14 anos: implicações 
para o ensino de História. Rio de Janeiro, 1998. Dissertação (Mestrado) - PUC/RJ; SIMAN, L. M. de C. A construção do conhecimento, do raciocínio histórico e da cidadania nas crianças. IV ENCONTRO NACIONAL DE PESQUISADORES DO ENSINO DE HISTÓRIA, IV, 1999. Anais... Ijuí: Unijuí, 1999; OLIVEIRA, S. R. F. A noção de tempo histórico na criança: um estudo sobre a noção do passado, das idéias espontâneas relativas à história da civilização e da relatividade dos conhecimentos e julgamentos históricos em crianças de 7 a 10 anos. Marília, 2000. Dissertação (Mestrado) - Unesp/Marília; SIMAN, L. M. de C. A temporalidade histórica como categoria central do pensamento histórico: desafios para o ensino e a aprendizagem. In: ROSSI, V. L. S. de., ZAMBONI, E. Quanto tempo o tempo tem. Campinas: Alínea, 2003; DUTRA, S. F. As crianças e o desenvolvimento da temporalidade histórica. Belo Horizonte, 2003. Dissertação (Mestrado) - UFMG.

${ }^{25}$ CHESNEAUX, J. Devemos fazer tabula rasa do passado? São Paulo: Ática, 1995.

${ }^{26}$ Sobre esse histórico dos programas oficiais de História na História do Brasil, ver: ABUD, K. Currículos de História e políticas públicas: os programas de História do Brasil na escola secundária. In: BITTENCOURT, C. (Org.) O saber histórico na sala de aula. São Paulo: Contexto, 1998.

${ }^{27}$ Ibidem.

${ }^{28}$ Coletâneas contemporâneas que projetam uma revisão de paradigmas explicativos mais globais podem ser importantes instrumentos auxiliares, sobretudo para o professor que atua no ensino fundamental, no sentido de garantirem um redimensionamento de aspectos presentes nessa tendência hegemônica, tais como: LINHARES, M. Y. (Org.) História Geral do Brasil. Rio de Janeiro: Campus, 1990; FREITAS, M. C. (Org.) Historiografia brasileira em perspectiva. 4.ed. São Paulo: Contexto, 2001. 